\title{
A USER-FRIENDLY REMOTE-SENSING WEB-PLATFORM FOR BIODIVERSITY CONSERVATION AND MANAGEMENT IN PROTECTED AREAS
}

\author{
R. O. Chávez ${ }^{1 *}$, J. A. Lastra ${ }^{1}$, D. Valencia ${ }^{2}$, I. Díaz-Hormazábal ${ }^{2}$ \\ ${ }^{1}$ Laboratorio de Geo-Información y Percepción Remota, Instituto de Geografía, Pontificia Universidad Católica de Valparaíso. \\ Av. Brasil 2241, Valparaíso, Chile - roberto.chavez@pucv.cl-jose.lastra@pucv.cl \\ ${ }^{2}$ Sección de Monitoreo e Información del SNASPE, Gerencia de Áreas Silvestres Protegidas, Corporación Nacional Forestal, Chile. \\ Paseo Bulnes 259, Santiago, Chile. - diego.valencia@conaf.cl - ignacio.diaz@conaf.cl
}

KEY WORDS: npphen, shiny, MODIS, essencial biodiversity variables, phenology

\begin{abstract}
The Chilean SNASPE is a complex network of 104 protected areas covering 18.5 million hectares of continental and insular Chile in South America. The geographical complexity and high biodiversity of the SNASPE make difficult to develop a unified monitoring system for conservation and management. In this contribution, we introduce a novel and remote-sensing web-platform for monitoring SNASPE units based completely in open acces data and software. The platform was designed in close cooperation with the Chilean forest service CONAF in order to make it applicable to the whole SNASPE. Following the framework of the Group on Earth Observation - Biodiversity Observation Network (GEO-BON), we used the Essential Biodiversity Variable (EBV) Phenology and MODIS Enhanced Vegetation Index (EVI) data to detect in near-real-time anomalies from the normal annual phenological cycle of vegetation. The platform is based on a flexible non-parametric probabilistic algorithm (the "npphen" R package) capable to reconstruct any type of leaf phenology and to quantify its inter-annual variation by means of confidence intervals around the most probable annual curve. Phenological anomalies are then calculated as a deviation from the expected annual cycle and judged based on their location within the confidence intervals. Anomalies located above 95\% confidence interval trigger a "red alert" which is displayed on the web application as soon as the MODIS data become available. This user-friendly platform was implemented in the La Campana National Park giving early alerts of a severe drought in 2019, warning Conaf to implement actions to protect the park from potential wild fires.
\end{abstract}

\section{INTRODUCTION}

The Group on Earth Observation - Biodiversity Observation Network (GEO-BON) is a global initiative aimed at developing an integrated and interoperable biodiversity observation system to support decision-making at multiple scales (from local to global) (Gill et al., 2014). To achieve this ambitious goal, GEOBON has suggested 22 candidate EBVs as an effort to harmonize biodiversity monitoring at a global scale (Pereira et al., 2013; Vihervaara et al., 2017). One of these EBV is Phenology, or the recurring seasonal life cycle of plants, which according to IPCC, is one of the simplest and most efficient ways to detect and geographically spatialize the effects of climate change on vegetation (IPCC, 2013). In this paper, we use the EBV Phenology, specifically leaf phenology, and open access remote sensing data and software to provide a robust phenological baseline and to implement a monitoring system for different vegetation types in protected areas.

In 2015 Conaf incorporated the Open Standards for the Practice of Conservation (CMP, 2007) in the planning and management of the Chilean network of protected areas SNASPE. These standards, developed by the Conservation Measures Partnership (CMP) - a consortium of conservation organizations -, place special efforts in developing monitoring systems and indicators to evaluate conservation practices for each cycle of adaptative management (CMP, 2007; Schwartz et al., 2012). A critical step is the definition of "conservation targets" (in Spanish "objetos de conservación", OdeC) and their threats. OdeC can be species or ecosystems within a protected area. The evaluation of OdeC conservation status is carried out by selecting "key ecological attributes" (in Spanish "atributos ecológicos clave", AEC), defined as an ecological or biological aspect of the OdeC, which in the case of being absent or altered, indicates loss or degradation through time. AEC must be sensitive to changes, measurable, precise and consistent through time (CMP, 2007). Additionally, international standards such as GEO-BON require that AEC should be reliable and comparable through sites. To achieve this, Conaf strategy for conservation monitoring has focused on the following lines: standarized designs, organizational structure, societal and academia engagement, funding and administration, training and strategic communication. The use of the EBV Phenology accomplishes all the desired attributes for a AEC for natural vegetation ecosystems (OdeC) of the Chilean SNASPE. Its implementation as a remote sensing based web-portal system is the result of an alliance between Conaf and the Laboratory of Geo-information Science and Remote Sensing of the Institute of Geography in the Pontificia Universidad Católica de Valparaíso.

Phenological dynamics of vegetation depend closely on inter and intra-annual changes of temperature and water availability (Ault et al., 2015; Myneni et al., 1997; Schwartz, 1999; Zhang et al., 2004), and therefore, react rapidly to the effects of global warming. In the last decade, satellite remote sensing has contributed enormously to understand large scale phenological dynamics under a climate change scenario (Myneni et al., 1997; Schwartz, 1999; Xiao et al., 2009). Land surface phenology (LSP) defined as "the seasonal pattern of variation in vegetated land surfaces observed from remote sensing" (Friedl et al., 2006), is reconstructed using time series of vegetation greenness retrieved by sensors on board of a satellite platforms. LSP is based on time series of vegetation indices (e.g. NDVI, EVI) calculated from spectral bands of optical sensors such as

Corresponding author 
AVHRR, SPOT vegetation, Landsat, Sentinel2 and MODIS, sensitive to variations in green biomass (de Beurs and Henebry, 2010). Thus, the phenological reconstruction is representative of all vegetation types present within the area measured by the sensor, and therefore, it is defined by the spatial resolution (or pixel size) of the satellite image (Friedl et al., 2006). This way, LSP differs from the traditional vegetation phenology concept which center is focused on a given plant species, land use or plant functional type. Strictly speaking, LSP is equivalent to the leaf vegetation phenology only when the pixel at the ground level is covered by a single vegetation type. Despite the limitations of having a mixed signal, LSP constitutes the only possible approximation to quantify seasonal phenological dynamics over large areas and it is considered the simplest and most efficient way to assess the effects of climate change (Ganguly et al., 2010; Zhang et al., 2007) and other natural or anthropogenic disturbances (Morellato et al., 2016). Therefore, monitoring LSP using freely available remote sensing data is a cost-efficient way to evaluate the status of conservation targets over large areas (Hargrove et al., 2009).

\subsection{Objectives}

In this paper we introduce a novel web-platform based on satellite derived phenological reconstructions and anomaly detection using a flexible non-parametric approach, implemented in the "npphen" R package (Chávez et al., 2017). This approach has been used in phenological studies for different vegetation types (Chávez et al., 2019a; Chávez et al., 2019b; Estay et al., 2019), and therefore, it is a good alternative for complex networks of protected areas such as the case of the Chilean SNASPE. We show an example of the web-platform implemented for La Campana National Park in Central Chile, which was designed and constructed following the Chilean Forest Service (Conaf) requirements and guidelines to provide operational management indicators. We also provide a real example of how this user-friendly platform was used by Conaf staff to detect the increasing effects of a severe drought affecting the park.

\section{MATERIAL AND METHODS}

\subsection{The Chilean SNASPE}

The Chilean network of protected areas, in spanish "Sistema Nacional de Áreas Silvestres Protegidas del Estado" SNASPE comprises 104 areas categorized in National Parks, National Reserves and Natural Monuments, which altogether cover an area of 18.5 million ha, spanning from $18^{\circ} \mathrm{S}$ to $55.9^{\circ} \mathrm{S}$ (Figure 1). Since 1974 the Chilean forest service Conaf is the intitution in charge of the SNASPE administration.

\subsection{La Campana National Park}

The La Campana national park is located in the Chilean coastal range in the Valparaíso region (Central Chile) between $32.91^{\circ}$ and $33.02^{\circ} \mathrm{S}$ and $71.15^{\circ}$ and $71.01^{\circ} \mathrm{W}$ (Figure 2) covering 8,000 ha. This protected area, declared a UNESCO biosphere reserve in 1985, is a relevant floristic convergence spot of phytogeographic elements from Central Chile ecosystems, and therefore, an area of high interest for biodiversity conservation (Myers et al., 2000).

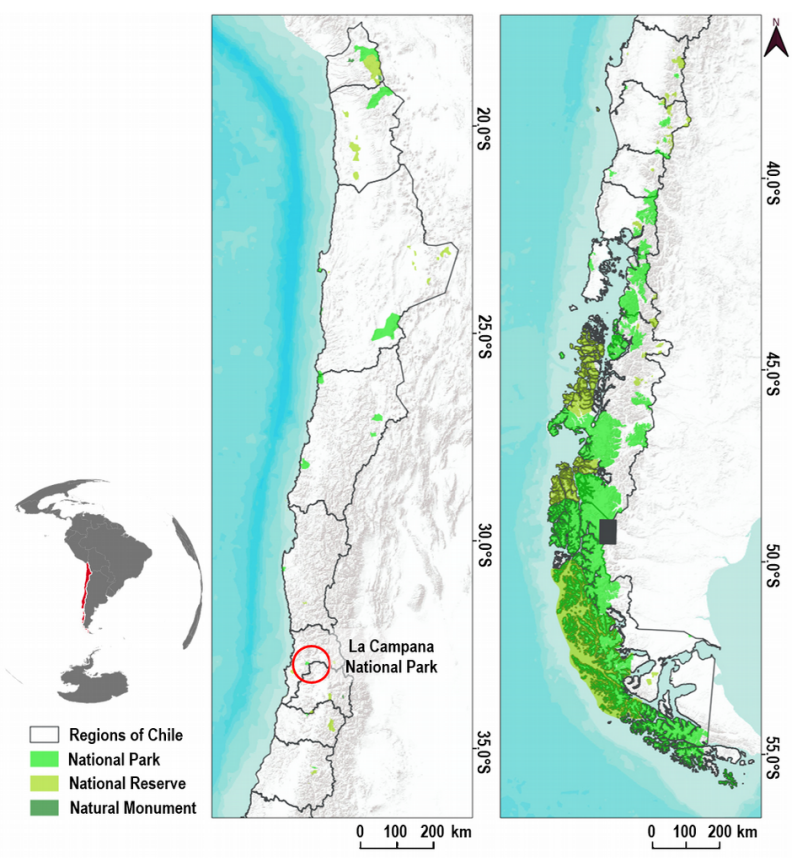

Figure 1. Chilean network of protected areas SNASPE.

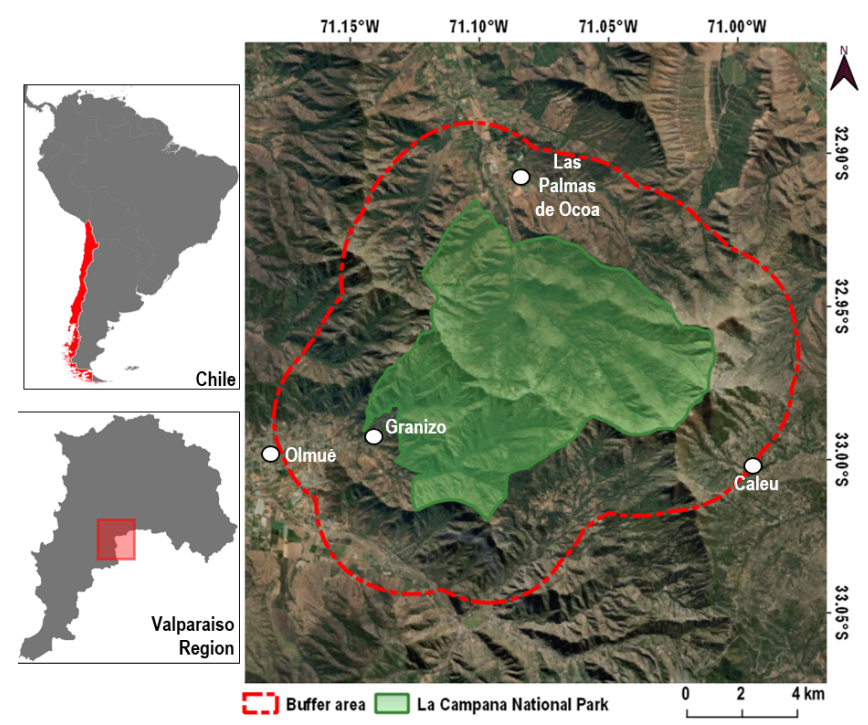

Figure 2. La Campana National Park where the web-platform was implemented in December 2018

In 2017, Conaf updated the management plan of the park using the CMP Open Standards (CONAF, 2017) in which the following OdeC were identified: 1) Sclerophyll forest and shrubland: representative of the Central Chile natural ecosystem, considered a biodiversity hotspot and heavily threatened considering that this is the most populated area of the country; 2) Nothofagus macrocarpa forests: decideous forest dominated by $N$. macrocarpa, an endemic species of Central Chile, with restricted distribution and considered the most septentrional distribution of the complete Nothofagus genre in the American continent; 3) highland ecosystem: comprises low shrublands and grasslands steppes with presence of the rare Bromeliaceae species Puya coerulea; 4) xerophytic shrubland: dense thorny shrubland located in the dry north slopes of the park; 5) hygrophilic (wet) forest located near the streams or in wet south slopes; 6) Jubaea chilensis, an endemic 
palm tree species of Chile with limited distribution and the main conservation target for which the National Park was originally created in 1967

\subsection{Phenological reconstruction and anomaly detection using the "npphen package" $R$ package and MODIS data}

We use 16-day composites of the MODIS Vegetation Index product version 6, available at the USGS Earth Explorer geoportal, specifically the Enhanced Vegetation Index (EVI) product with $250 \mathrm{~m}$ pixel resolution. EVI is sensitive to vegetation green biomass (Huete et al., 2002) and has been proven useful for phenological studies (Jin et al., 2019; Xiao et al., 2006; Zhang et al., 2003). By combining MODIS EVI data from the Terra and Aqua satellite, we constructed a raster stack time series with 8-day temporal resolution spanning from 2000 until the present. We removed useless pixels based on the Quality Assessment bands of MODIS (clouds, cloud shadows, snow, ice and high levels of aerosols). We then reconstructed the annual phenology using a probabilistic and non-parametric approach (Estay and Chávez, 2018) implemented in the "npphen" R package (Chávez et al., 2017). In this approach, we consider all EVI data of 19 growing seasons (from july to june of the next year in the South Hemisphere ) to calculate an annual EVI phenological cycle. This is defined as the most frequent EVI value expected to each date along to their confidence intervals (see Figure 3, low-right panel) considering all historical records (the period between 12 -feb-2000 and 26june-2019; the last growing season of the reference period was 2018-2019). Using this annual phenology as a reference, we can calculate for the current growing season (2019-2020) the EVI anomaly (deviation from the expected value) and the position of the EVI observation on the confidence interval. This is calculated at a pixel basis and for each date of the current growing season. For example, a negative anomaly with the EVI observation falling outside the 0.95 region of the confidence ineterval is with a high confidence a detrimental condition (red alert). Contrastly, and even for negative anomalies, if the EVI observation falls on the confidence region below 0.75 or 0.5 , it is likely to be part of the natural variation of the phenological cycle (normal condition, thus no alerts are triggered).

\subsection{Platform implementation using R-shiny}

Once the phenology, anomaly and probability stacks were calculated for all dates, we implemented the web-platform using the Shiny R platform (Chang et al., 2019) and considering the OdeC of the park and the EBV "phenology" as AEC. The implementation involved two stages: (I) user interface programming (UI) where menus for input data, analysis options and output maps, plots and tables are displayed in a friendly interface, and (II) server configuration where data processing and MODIS data updating from last releases are carried out. UI and II are the main body of the web-app (app.R). The app implementation (app.R) considers a fully automated pixel based processing of MODIS data, including quality assesment analisys, phenology, anomaly and probability calculations. Negative anomalies $(<-0.05)$ are then classified as "caution" (pixels with yellow color in the UI map) if they fall in the $0.75-0.95$ probability region and "alert" (pixels with red color) if they fall in the $>0.95$ probability region (Figure 3 ). Positive anomalies $(>0.05)$ with probibility $>0.95$ are classified as "recovery" (pixel with green color). The App is available to internal and external users in the URL https://labgrs.shinyapps.io/SMF-1/. The App database is comprised by the following data sets: a) EVI Phenology (raster stack)

b) EVI raster stack (2000 - to present)

c) EVI anomalies raster stack (2000 - to present)

d) EVI probabilitites raster stack (2000 - to present)

e) Shapefiles of Park and buffer zone

\section{RESULTS}

\subsection{Features of the web-platform}

Figure 3 shows the main page of the web-platform. The screen on the upper right side display the base map and the borders of the La Campana National Park including a $3 \mathrm{~km}$ buffer. There are 4 layers in this map for displaying: a land cover showing the different OdeC, and the other 3 layers show pixels under "alert" (red), "warning" (yellow) and "recovery". These status correspond to the date indicated in the left panel. By default the platform shows the results based on the most updated MODIS scene, although any historical date (8 day temporal resolution) can be displayed. In the left panel the user can also choose to display instead of the anomalis (red/yellow/green) the EVI value of the selected date.

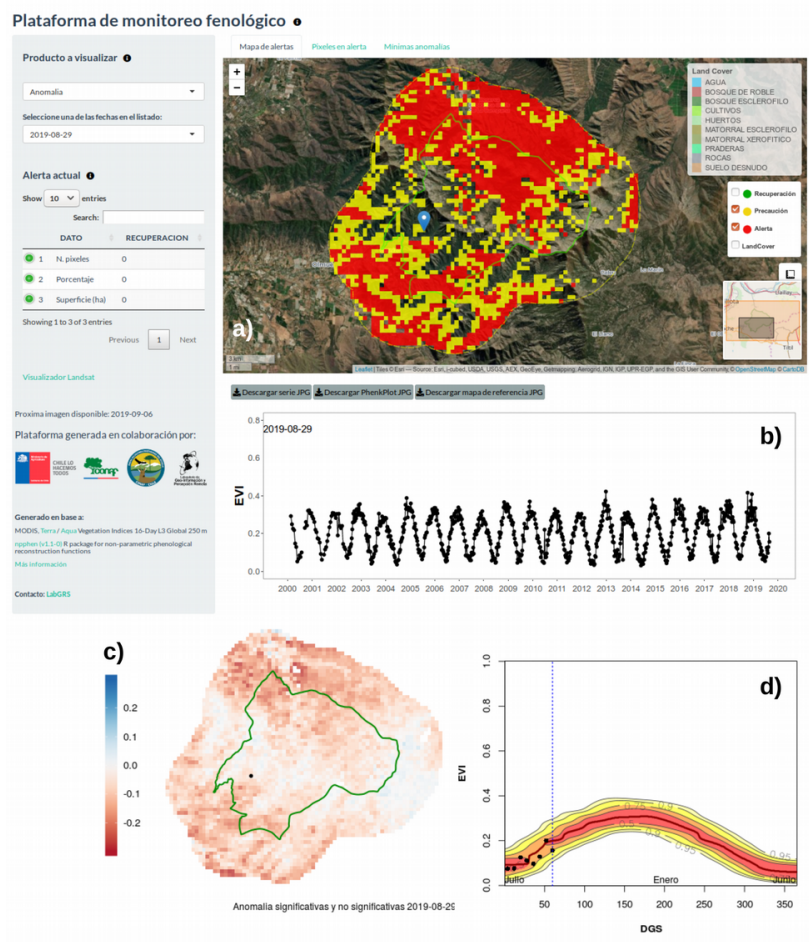

Figure 3. Web-platform main page displaying the a) warning map based on EVI anomalies and probabilities; b) EVI time series of a selected pixel; c) EVI anomaly map for the selected date; d) annual EVI cycle (2000-2018) with confidence intervals and the current growing season (dark dots)

If the user clicks on any point of the map, the historical EVI time series is displayed (Figure 3-b) together with its annual phenology (kernel density estimation using all EVI values of the previous GS's) along with the EVI values of the current growing season represented by black dots (Figure 3-d). Finally, the EVI anomaly map for the entire park and buffer is provided on the lower left part of the platform for the selected date (Figure 3-c). All maps and plots can be downloaded as JPG files by pressing the corresponding bottom in the screen. Secondary pages of the platform can be accessed by clicking the taps on top of the map. These socondary pages provide 
functionalities for summarizing data (e.g. a map with the maximum anomalies for a given period or a map with dates at which the EVI anomalies were maximum also for a given period, tables indicating the area affected by different levels of phenological anomalies per OdeC.

\subsection{Near-real time detection of the 2019-2020 drought}

The web-platform was delivered to Conaf in 2019 and it has been operation since then. During the first dates of the 20192020 GS (early July 2019), the web platform showed the first effects of an unprecedented drought in Central Chile (Figure 4).
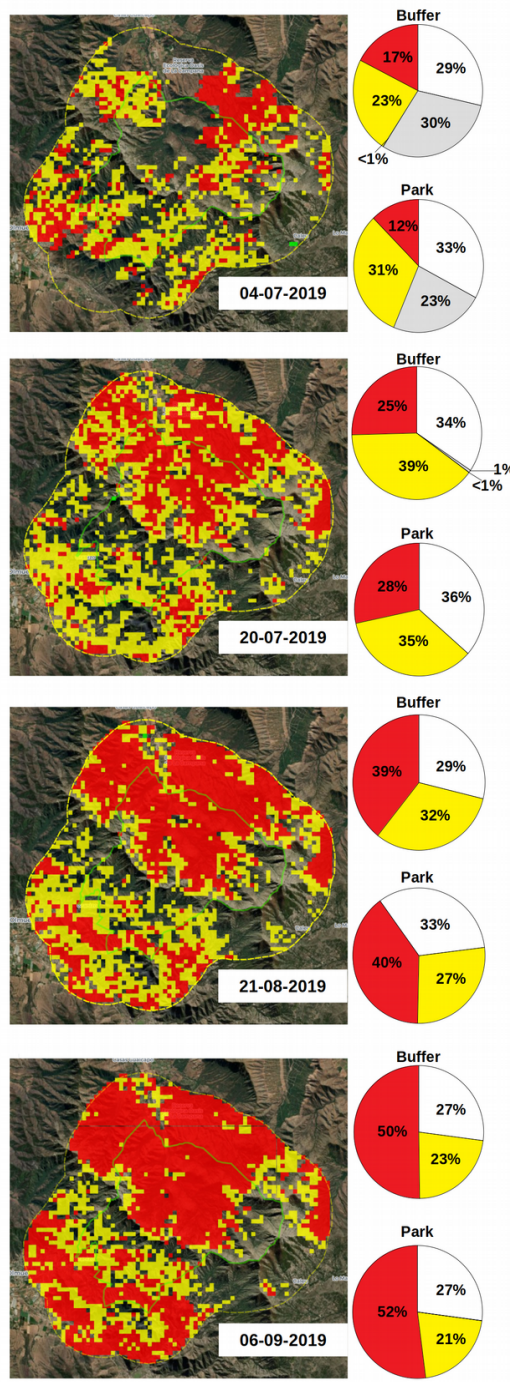

Figure 4. Warning system showing the effects of the 20192020 drought. red=alert $(\mathrm{P}>0.95)$; yellow=warning $(\mathrm{P}[0.75-0.95]) ;$ no color $=$ normal $(\mathrm{P}<0.75)$; grey $=$ clouds.

As early as July $4^{\text {th }}$, at least $12 \%$ of the park and $17 \%$ of the buffer zone were under "alert", i.e. with negative EVI anomalies located outside the lower 95\% confidence interval (Figure 4). At the same date, at least $31 \%$ of the park and $23 \%$ of the buffer zone were under "warning", i.e. entering the critical region of negative EVI anomalies within the 0.75 and 0.95 lower confidence interval. We say "at least" since $30 \%$ of the MODIS pixels at this date were covered by clouds and the affected area could have been more. By July $20^{\text {th }} 28 \%$ of the park were under "alert" (red) and 35\% were under "warning" (yellow) showing and increasing trend and by September $6^{\text {th }}$ $52 \%$ of the park was already under "alert", $27 \%$ under warning and only $27 \%$ under "normal" conditions. From the area considered as "normal" at the beginning of September, most is covered by decideous Nothofagus macrocarpa forests, which have not yet diplayed their leaves fully, and therefore, it was too soon to verify whether it has been affected by droughtor not.

\section{DISCUSSION}

LSP, or the recurring seasonal 'greening' and 'browning' cycle of the vegetated surface, has been proposed as one of the EBV in the framework of the Convention on Biological Conservation (Skidmore et al., 2015), and according to IPCC is one of the simplest and most efficient way to detect and geographically spatialize the effects of climate change on vegetation. Currently, satellite imagery make possible cost-efficient monitoring of LSP at different spatial and temporal scales (de Beurs and Henebry, 2005; Jin et al., 2019; Jong et al., 2012; Liang and Zhang, 2015; Wingate et al., 2015), but available parametric methods are limited to describe annual cycles of all vegetation types and lack a reliability measure (de Beurs and Henebry, 2010). Here, we introduce a LSP monitoring system for conservation purposes based on (a) the 'npphen' R-package for LSP reconstruction and anomaly detection using nonparametric techniques, (b) the 'shiny' R-package for web mapping implementation and (c) open access MODIS EVI data.

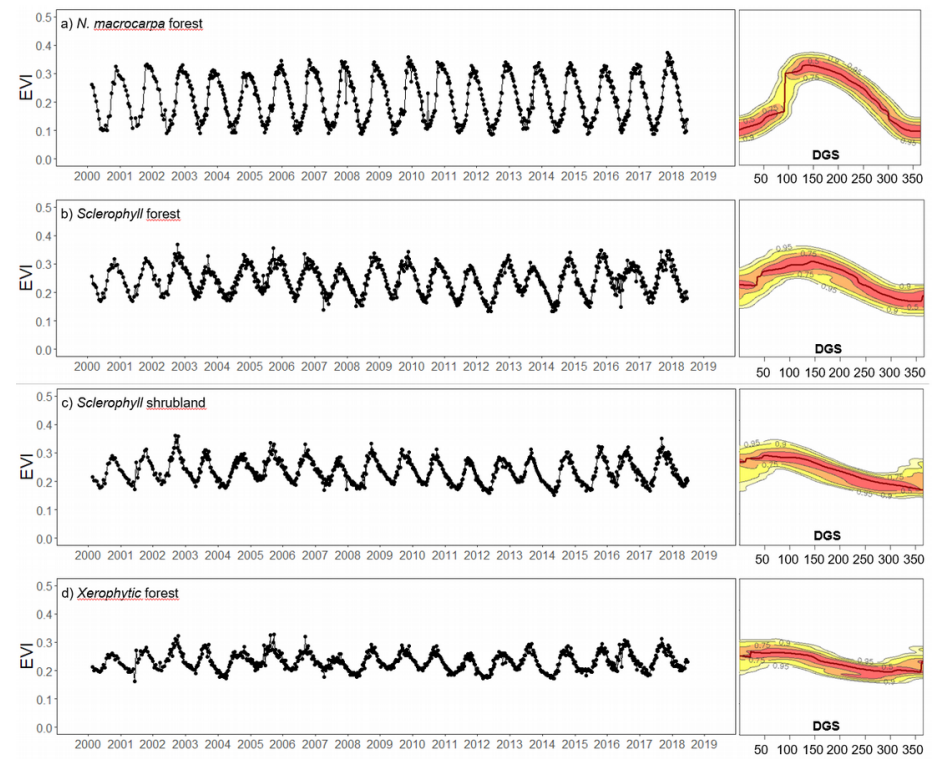

Figure 5. EVI time series and long-term annual phenology (2000-2019) reconstructed using the median values of all pixels corresponding to four conservation targets (OdeC) of the La Campana National Park.

Advantages of the 'npphen' approach are: its flexibility to describe any LSP annual pattern (see Figure 5, with reconstruction of OdeC of the La Campana National Park with distinctive annual phenologies), it handles time series or raster stacks with and without gaps (the calculation of the reference phenology and confidence intervals does not require gap filled data or smooting pre-process as many parametric methods do, e.g. TIMESAT (Jin et al., 2019; Jönsson and Eklundh, 2004)), and above all, it provides confidence interval for the expected LSP, useful to judge anomaly magnitudes. These features make our approach a robust option for a unified monitoring system for complex networks of protected areas, such as the Chilean 
SNASPE, with a large range of phenological dynamics are present. At the present time, similar platforms as the one presented here are under construction for other three SNASPE units. Complementary, a network of Phenocams (Brown et al., 2016) is being installed in the same parks, including La Campana, to validate the remote sensing observation with field data and also to contribute to International Phenological Monitoring Networks (e.g. Pheno Cam or EuroPhen).

For operational purposes, the fact that the "npphen" calculates not only anomalies from the normal phenology, but also a measure of confidence, allows the implementation of robust management indicators for biodiversity conservation. It is clear that anomalies alone do not provide evidence of disturbances (Chávez et al., 2019; de Beurs and Henebry, 2010), since vegetation types with high inter annual phenological variation, can show large anomalies which still fall within the range of normal historical values. Interannual phenological variability is a species specific dependent feature. In this study, and after thorough discussions with Conaf staff, we developed a simple classification of EVI anomalies using three categories: "alert" (red) showing a condition where vegetation shows a level of green biomass lower than $95 \%$ of historical records, i.e. a very critical condition, "warning" (yellow) when approaching the "alert" condition with values falling in the range between the $75 \%$ and $95 \%$ of the more negative historical values, and finally, "recovery" when positive anomalies are flagged being values higher than the $95 \%$ of historical records. This last category was important to Conaf to monitor and report the effect of restoration practices. The web-platform was then designed to provide simple and more elaborated information. The simple three-color map provides at a first glance a complete picture of the most updated phenological condition of all vegetation types of the park along with a summary of the porcentage of the area under the three conditions. By manipulating other available options of the platform, more advanced users can plot and download maps and tables with summaries per OdeT and different period of times, which are useful inputs for reporting and management of the protected area.

Once the La Campana National Park web-platform became operational, Conaf was able to quantify in near real time (few days delay) the effects of a serious drought affecting central Chile during the 2019-2020 GS. Areas under "alert" have very dry vegetation, increasing the risk of wild fires in an area where massive wild fires have occurred in recent times (Bowman et al., 2019). Since then, several actions have been taken to minimize the risk of wildfires within the park and surrounding areas: no overnight camping is allowed in the park for the entire Summer and the use of stoves or any other heating sources are forbidden. Besides, a landing and water supply area has been implemented for fire aerial firefighting helicopters. Rangers surveillance rounds have increased to warn visitors about the fire risk, report early ignitions points or to support emergency evacuation protocols. Conaf is also collaborating with local communities to organize environmental education activities regarding biodiversity conservation, water use efficiency and wildfire risks.

\section{CONCLUSION}

We developed a fully-automated web-platform to monitor the EBV phenology as a key ecological atribute of the vegetation conservation targets of the La Campana National Park in Central Chile. Using a probabilistic non-parametric approach, we quantify anomalies from the normal annual phenological cycle and, different from alternative parametric approaches, our method also provides a significance measure of the observed anomaly based on historical records. The non-parametric nature of this approach allowed us to provide a robust and simple warning systems where "red" alerts are given when negative anomalies are below the $95 \%$ of historical observations for a given day of the year. The platform provides a three colors map showing in a simple manner the status of all conservation targets. Due to its flexible nature, the method allows phenological reconstructions and confidence interval calculations of all type of vegetation, providing a unified warning system applicable to complex networks of conservation areas such as the Chilean SNASPE.

\section{ACKNOWLEDGEMENTS}

This research was funded by Fondecyt de Iniciación grant $\mathrm{N}^{\circ}$ 11171046 and Proyecto SIMEF código 2. The authors also want to thanks to the La Campana National Park rangers (guardaparques) for $t$ supporting this project.

\section{REFERENCES}

Ault, T.R., Schwartz, M.D., Zurita-Milla, R., Weltzin, J.F., Betancourt, J.L., 2015. Trends and natural variability of spring onset in the coterminous united states as evaluated by a new gridded dataset of spring indices. J. Clim. 28, 8363-8378. https://doi.org/10.1175/JCLI-D$14-00736.1$

Bowman, D.M.J.S., Moreira-Muñoz, A., Kolden, C.A., Chávez, R.O., Muñoz, A.A., Salinas, F., GonzálezReyes, Á., Rocco, R., de la Barrera, F., Williamson, G.J., Borchers, N., Cifuentes, L.A., Abatzoglou, J.T., Johnston, F.H., 2018. Human-environmental drivers and impacts of the globally extreme 2017 Chilean fires. Ambio. https://doi.org/10.1007/s13280-018$1084-1$

Brown, T.B., Hultine, K.R., Steltzer, H., Denny, E.G., Denslow, M.W., Granados, J., Henderson, S., Moore, D., Nagai, S., SanClements, M., Sánchez-Azofeifa, A., Sonnentag, O., Tazik, D., Richardson, A.D., 2016. Using phenocams to monitor our changing Earth: toward a global phenocam network. Front. Ecol. Environ. 14, 84-93. https://doi.org/10.1002/fee.1222

Chang, W., Cheng, J., Allaire, J., Xie, Y., McPherson, J., 2019. shiny: Web Application Framework for RR package version 1.4. 0 .

Chávez, R.O., Estay, S.A., Riquelme, G., 2017. npphen. Vegetation Phenological Cycle and Anomaly Detection using Remote Sensing Data. UACH, PUCV, Chile.

Chávez, R.O., Moreira-Muñoz, A., Galleguillos, M., Olea, M., Aguayo, J., Latín, A., Aguilera-Betti, I., Muñoz, A.A., Manríquez, H., 2019. GIMMS NDVI time series reveal the extent, duration, and intensity of "blooming desert" events in the hyper-arid Atacama Desert, Northern Chile. Int. J. Appl. Earth Obs. Geoinf. 76, 193-203. https://doi.org/10.1016/J.JAG.2018.11.013

Chávez, R. O., Rocco, R., Gutiérrez, Á.G., Dörner, M., Estay, S.A., 2019. A self-calibrated non-parametric time series analysis approach for assessing insect defoliation of broad-leaved deciduous Nothofagus pumilio forests. Remote Sens. 11. https://doi.org/10.3390/rs 11020204

CMP, 2007. Open Standards for the Practice of Conservation, Version 2.0 ID-131.

CONAF, 2017. Plan de manejo del Parque Nacional La Campana. 
de Beurs, K.M., Henebry, G.M., 2010. Spatio-temporal statistical methods for modelling land surface phenology, in: Phenological Research. Springer, pp. 177-208.

de Beurs, K.M., Henebry, G.M., 2005. A statistical framework for the analysis of long image time series. Int. J. Remote Sens. 26, 1551-1573. https://doi.org/10.1080/01431160512331326657

Estay, S.A., Chávez, R., 2018. npphen: an R-package for non-parametric reconstruction of vegetation phenology and anomaly detection using remote sensing. bioRxiv 301143.

Estay, S.A., Chávez, R.O., Rocco, R., Gutiérrez, A.G., 2019. Quantifying massive outbreaks of the defoliator moth Ormiscodes amphimone in deciduous Nothofagusdominated southern forests using remote sensing time series analysis. J. Appl. Entomol. 143, 787-796. https://doi.org/10.1111/jen.12643

Friedl, M., Henebry, G., Reed, B., Huete, A., White, M., Morisette, J., Nemani, R., Zhang, X., Myneni, R., 2006. Land surface phenology. A Community White Pap. requested by NASA 10.

Ganguly, S., Friedl, M.A., Tan, B., Zhang, X., Verma, M., 2010. Land surface phenology from MODIS: Characterization of the Collection 5 global land cover dynamics product. Remote Sens. Environ. 114, 18051816. https://doi.org/10.1016/J.RSE.2010.04.005

Gill, M., Pereira, H., Geller, G., Walters, M., 2014. GEO BON Strategic Workplan 2014-2016.

Hargrove, W.W., Spruce, J.P., Gasser, G.E., Hoffman, F.M., 2009. Toward a national early warning system for forest disturbances using remotely sensed canopy phenology. Photogramm. Eng. Remote Sens. 75 11501156.

Huete, A., Didan, K., Miura, T., Rodriguez, E.P., Gao, X., Ferreira, L.G., 2002. Overview of the radiometric and biophysical performance of the MODIS vegetation indices. Remote Sens. Environ. 83, 195-213. https://doi.org/10.1016/S0034-4257(02)00096-2

IPCC, 2013. Climate Change 2013. The physical science basis.

Jin, H., Jönsson, A.M., Olsson, C., Lindström, J., Jönsson, P., Eklundh, L., 2019. New satellite-based estimates show significant trends in spring phenology and complex sensitivities to temperature and precipitation at northern European latitudes. Int. J. Biometeorol. 63, 763-775. https://doi.org/10.1007/s00484-019-01690-5

Jong, R., Verbesselt, J., Schaepman, M.E., Bruin, S., 2012. Trend changes in global greening and browning: contribution of short $\square$ term trends to longer $\square$ term change. Glob. Chang. Biol. 18, 642-655.

Jönsson, P., Eklundh, L., 2004. TIMESAT - a program for analyzing time-series of satellite sensor data. Comput. Geosci. 30 , $833-845$. https://doi.org/10.1016/J.CAGEO.2004.05.006

Liang, L., Zhang, X., 2015. Coupled spatiotemporal variability of temperature and spring phenology in the Eastern United States. Int. J. Climatol.

Morellato, L.P.C., Alberton, B., Alvarado, S.T., Borges, B., Buisson, E., Camargo, M.G.G., Cancian, L.F., Carstensen, D.W., Escobar, D.F.E., Leite, P.T.P., Mendoza, I., Rocha, N.M.W.B., Soares, N.C., Silva, T.S.F., Staggemeier, V.G., Streher, A.S., Vargas, B.C., Peres, C.A., 2016. Linking plant phenology to conservation biology. Biol. Conserv. 195, 60-72. https://doi.org/10.1016/J.BIOCON.2015.12.033
Myers, N., Mittermeier, R.A., Mittermeier, C.G., da Fonseca, G.A.B., Kent, J., 2000. Biodiversity hotspots for conservation priorities. Nature 403, 853-858. https://doi.org/10.1038/35002501

Myneni, R.B., Keeling, C.D., Tucker, C.J., Asrar, G., Nemani, R.R., 1997. Increased plant growth in the northern high latitudes from 1981 to 1991 . Nature 386, 698.

Pereira, H.M., Scharlemann, J.P.W., Al, E., 2013. Essential biodiversity variables 277 https://doi.org/10.1126/science.1229931

Schwartz, M.D., 1999. Advancing to full bloom: planning phenological research for the 21st century. Int. J. Biometeorol. 42, 113-118.

Schwartz, M.W., Deiner, K., Forrester, T., Grof-Tisza, P., Muir, M.J., Santos, M.J., Souza, L.E., Wilkerson, M.L., Zylberberg, M., 2012. Perspectives on the Open Standards for the Practice of Conservation. Biol. Conserv. 155, 169-177. https://doi.org/10.1016/J.BIOCON.2012.06.014

Skidmore, A.K., Pettorelli, N., Coops, N.C., Geller, G.N., Hansen, M., Lucas, R., Mücher, C.A., O'connor, B., Paganini, M., Pereira, H.M., 2015. Environmental science: Agree on biodiversity metrics to track from space. Nat. News 523, 403.

Vihervaara, P., Auvinen, A.-P., Mononen, L., Törmä, M., Ahlroth, P., Anttila, S., Böttcher, K., Forsius, M., Heino, J., Heliölä, J., Koskelainen, M., Kuussaari, M., Meissner, K., Ojala, O., Tuominen, S., Viitasalo, M., Virkkala, R., 2017. How Essential Biodiversity Variables and remote sensing can help national biodiversity monitoring. Glob. Ecol. Conserv. 10, 4359. https://doi.org/10.1016/J.GECCO.2017.01.007

Wingate, L., Ogée, J., Cremonese, E., Filippa, G., Mizunuma, T., Migliavacca, M., Moisy, C., Wilkinson, M., Moreaux, C., Wohlfahrt, G., 2015. Interpreting canopy development and physiology using the EUROPhen camera network at flux sites. Biogeosciences Discuss.

Xiao, X., Hagen, S., Zhang, Q., Keller, M., 2006. Detecting leaf phenology of seasonally moist tropical forests in South America with multi-temporal MODIS images 103 , https://doi.org/10.1016/j.rse.2006.04.013

Xiao, X., Zhang, J., Yan, H., Wu, W., Biradar, C., 2009. Land surface phenology, in: Phenology of Ecosystem Processes. Springer, pp. 247-270.

Zhang, X., Friedl, M.A., Schaaf, C.B., Strahler, A.H., 2004. Climate controls on vegetation phenological patterns in northern mid $\square$ and high latitudes inferred from MODIS data. Glob. Chang. Biol. 10, 1133-1145.

Zhang, X., Friedl, M.A., Schaaf, C.B., Strahler, A.H., Hodges, J.C.F., Gao, F., Reed, B.C., Huete, A., 2003. Monitoring vegetation phenology using MODIS. Remote Sens. Environ. 84, 471-475. https://doi.org/10.1016/S0034-4257(02)00135-9

Zhang, X., Tarpley, D., Sullivan, J.T., 2007. Diverse responses of vegetation phenology to a warming climate. Geophys. Res. Lett. 34 